\title{
Automation of the work environment and the human-technology collaboration challenge: a critical reflection
}

\begin{abstract}
This paper reflects on the need for designing automated systems that can lead to the creation of work organization that professes social harmony between the automated technical and the human systems towards enhanced productivity. The aim is to argue for the development of the requisite knowledge in the application of digitized/ automated systems that allows for open collaboration between the technological functions and the workforce that will make cross value chain optimization a reality. It is posited analytic strategies for examining mediated action between the human and an automated system can be made possible by isolating its elements. Such isolation allows various specialized perspectives to bring their insights to bear, and also serves as key to understanding how change occurs in the mediated action. Through such understanding, an innovative work organization that enhances social collaboration between automated systems and humans can be designed towards increased productivity.
\end{abstract}

Keywords: automated systems, social harmony, automated technical, automated systems, technological functions
Volume 3 Issue 6 - 2017

\author{
Mohammed Aminu Sanda,' Mohami \\ 'Department of Organization and Human Resource \\ Management, University of Ghana Business School, Ghana \\ ${ }^{2}$ Department of Business Administration, Technology and Social \\ Sciences, Luleå University of Technology, Sweden
}

Correspondence: Mohammed-Aminu, Department of Organization and Human Resource Management, University of Ghana Business School, Ghana, Email masanda@ug.edu.gh

Received: November 02, 2017 | Published: December II, 2017

\section{Introduction}

There is the concern that despite many promising production concepts, organizational models and development of new technologies during the last decades, the mining industry faces a large gap between expectations and real implementation. ${ }^{1}$ There is also the realization that increased automation, combined with an ever tougher global competition, will lead large industrial companies to rely on a lean organization with multi-skilled workers capable of managing multiple areas of the business, with technology and work built around 'autonomation', where people and machines cooperate. ${ }^{2}$ In this respect therefore, process automation and remote operation technologies in automated work will enable smarter, and more integrated automated work systems. The expectation here is to make the automated work system of the future become a substantially different place to that of today. Yet, there prevails the problem of how to model such intelligent production systems of the "future automated work systems" for them to become enablers for learning and collaboration across organizational borders. Abrahamsson et al., ${ }^{3}$ has observed that even if the idea of a holistic perspective on production systems is commonplace in most research areas of today, there is a true challenge in multidisciplinary research that reconnect the research fields and their theories, methods, ideas and results. This, on the one hand, reinforces the prevailing problem of developing a holistic work organization model to guide the future integration of the deep-mining companies' technical, organizational and human systems. On the other hand, it reinforces the challenge of developing deep-specialized knowledge in areas associated with each of these systems (i.e. technical, organizational and human) that could contribute towards the attainment of a visualized (or hypothesized) automated work system of the future (i.e. an Intelligent-work system) as it will be highlighted in the section below.

\section{Human factors in the automated value chain}

Most industries have for the past decade been confronted by number of challenges covering the whole mining and minerals which must be addressed, As such, industries need new mental images of themselves based on newly automated technologies with a modern work organization that supports high productivity as well as good working and social conditions. ${ }^{3}$ Process automation and remote operation technologies has enabled smarter, more integrated production systems. These automated systems have become enablers for learning and collaboration across organizational borders. ${ }^{3}$ Increased automation, combined with an ever tougher global competition, is now leading large industrial companies to rely on lean work organizations with multi-skilled workers capable of managing multiple areas of the business. This is because; the technologies being used and the work whose performance they facilitate are built around 'autonomation', where people and machines cooperate. Thus while the industry is progressively developing ground support systems for static and dynamic load cases, development of work methods and equipment could also be arranged to reduce the human exposure to risks as the work systems transit from mechanization to full automation, since the mode of work activity changes with technological changes. In such work activity the subject is the individual who is simultaneously engaged in physical activity (through the manipulation of digitized computer technology to programme robotic work tasks) as well as engaged in mental activity (through digitized communication models, by listening to background music during work, information transmission from the control centres, and/or from colleagues approaching or leaving the individuals activity location). The questions that emerge in this respect are as follows:

a. How does the digitization of human work affect individual's 
performance of object-oriented activity, if the object of the digitized work activity entails both physical (using technological tools to perform work) and mental (listening to communication models) efforts?

b. How does the digitization of human work affect the individual's subject-oriented activity, if social interaction in the digitized work activity entails collaboration between the human's physical activity and mental activity?

c. Does the use of technology as a mediating object of digitized activity, and also as a socializing tool impact on the motivation of individuals engage in a work activity?

d. How can operators tacit knowledge be captured and incorporated in future designs of digitized work activities

The questions above brings to the fore the issue that the digitization of the work system must not only concern the design of systems/ automation that are adapted to humans, but to regard humans as resources, as a possibility of designing better automated systems (i.e. intelligent automation). The understanding here is that; an automated work system must be seen to consists of a harmonious integration of the human and technological components of the system (i.e. it must be seen to consist of production processes and infrastructure that enhances not only human work, but also enables and learning.

\section{Actual human fit in automated work system}

According to Jarzabkowski, ${ }^{4}$ concerns over the gap between the theories of what people do and what people actually do has given rise to the 'practice' approach in management literature which focuses on the way that actors interact with the social and physical features of context in the everyday activities that constitute practice. She notes that a theory of practice brings reclusiveness and adaptation into a dialectic tension in which the two are inextricably linked. She explains that practice does not occur only in macro contexts which provide commonalities of action, but also in micro contexts in which action is highly localized. She therefore, sees the interaction between these contexts to provide an opportunity for adaptive practice. In this regard, Jarzabkowski ${ }^{4}$ concludes that the theoretical rationale for the study of practices may be found in activity theory whose framework provides a dynamic view of strategic practices and their role in organizational continuity or change.

According to Bannon, ${ }^{5}$ tools shape the way human beings interact with reality. He relates this to the principle of internalization/ externalization which, firstly notes that shaping external activities ultimately results in shaping internal ones. The principle also notes that, tools usually reflect the experiences of other people who have tried to solve similar problems at an earlier time and invented/ modified the tool to make it more efficient. This experience, from the perspectives of Bannon, is accumulated in the structural properties of tools (shape, material, etc.) as well as in the knowledge of how the tool should be used. He notes that tools are created and transformed during the development of the activity itself and carry with them a particular culture - the historical remnants from that development. So, the use of tools is a means for the accumulation and transmission of social knowledge. It influences the nature, not only of external behaviour, but also of the mental functioning of individuals.

Based on the notion that an automated system consists of technical components, information, materials and humans, then there is the need for holistic perspectives to be included in the design of the system's work organization. In this respect, macro ergonomics knowledge becomes relevant. Conceptually, macro ergonomics may be defined as a top-down socio technical systems approach to the design of the work systems, and the carry-through of the overall work system design to the design of the human-job, human-machine, and human-software interfaces. ${ }^{6}$ Macro ergonomics is concerned with human-organization interface technology. The empirical science supporting it is concerned with factors in the organization's technological subsystem, personnel subsystem, external environment, and the interactions of these factors as they impact on work system design. ${ }^{6}$ In this respect, this research discussion concerns the design of work organization systems where "hazard preventive planning", "risk reduction/elimination planning", and "technological and behavioral change processes" are key components. It is also about the development of technology for measurement and process management, organizational design and learning for operators. This therefore, requires the creation of a harmony between the technical and the social system, and whose creation can be facilitated by a holistic view of the system's functions. The significance of such harmony creation is defined by the realization that in order to enhance the development of intelligent automation systems for industrial firms, there is a need for the creation of knowledge on the harmonious integration of technological, organizational and human systems. This is because such integration will stand to provide the basis for the evolution of a community of practice at the workplace. In a 'community of practice' individual thought is essentially social and is developed in interaction with the practical activities of a community, through living and participating in its experiences over time. ${ }^{7}$ Thus, to understand practice, it is important to move beyond institutional similarities to penetrate the situated and localized nature of practice in particular contexts. Practice is seen as local and situated, arising from the moment-by-moment interactions between actors, on one hand, and between actors and the environments of their action, on the other hand.

The issue here is not only about designing systems/automation that is adaptable to humans, but to regard humans as resources, as a possibility of designing better systems (intelligent automation). The understanding here is that a work organization system must be seen to consists of humans/people and technology (i.e. it must be seen to consist of production processes, infrastructure and flows of digital signals, information, material, energy, products as well as human work and learning). In such system, there is always a sense of an ongoing process of social becoming that is realized through a chain of social events, or practice and all of these aspects must be in tune. Therefore overall knowledge is needed in the work system design and its parts, especially on how to harmoniously integrate the human and the other systems in the value chain (i.e. to be able to see the human as an integrated part of the system, an asset). The implication here is that, rather than looking for structural invariants, normative rules of conduct, or preconceived cognitive schema, ${ }^{4}$ it is important to investigate the processes whereby particular, uniquely constituted circumstances are systematically interpreted so as to render meaning shared. This represent a paradigm shift from traditional organization theory in which more concern is directed towards harnessing members behaviours in the interests of fulfilling organizational goals than in considering the costs to individuals of organizations' structural constraints.

In the light of the above observations, the Systemic-structural activity theory (SSAT), a modern synthesis within activity theory 
which brings together the cultural-historical and systems-structural strands of the tradition with findings and methods from Western human factors/ergonomics and cognitive psychology ${ }^{8}$ can be used to guide the development of a conceptual framework for crafting an innovative work organization model for the automated work systems. The SSAT entails the conceptual application of both organizational activity and macro ergonomics. The rationale for using these theoretical approaches are that these theories, in their own approaches, provide dynamic views of strategic practices in organizations, and also help explain the role of such practices in organizational change. ${ }^{4,9}$ In this regard therefore, an automated work system can firstly be theorized as organizational activity system. But as Adrich ${ }^{10}$ has argued, the theorization of organizations as activity systems have the tendency to bias thinking towards a concern for processes. According to Aldrich, many of these processes are goal-directed and boundary-maintaining, and these characteristics, in turn are central to the open-system or neutral-system model of organizations identified by Thompson ${ }^{11}$ as the emerging focus of organizational sociology.

Focusing on processes also makes salient the dialectical tension between members' behaviours, which threaten to push an organization into ultimately contradictory activities, and leaders' efforts at pulling members' contributions together into a coordinated whole. ${ }^{10}$ Also, since organizations possess technologies (i.e. techniques for processing raw materials and/or people) for accomplishing work, organizational activity then emphasizes a work system design in which technology affects social relations in organizations by structuring transactions between roles that are building blocks of an organization. In this respect, application of macro ergonomics theory stands to provide an understanding of the various processes to be entailed in an automated work system as organizational activity. This is because the goal of macro ergonomics theory is to help understand how to optimize a work system's design in terms of its socio technical system characteristics. Based on this understanding, the characteristics of the overall work system design can be carried down to the design of individual jobs, as well as human-machine and human-software interfaces in order to ensure a fully harmonized work system. When this goal is achieved, the results should be dramatic improvements in various aspects of organizational performance and effectiveness. ${ }^{6}$

Thus in the theorization of an automated work activity towards the development of an innovative work organization model, the mode of mining activity changes introduced by the technological changes must be understood. For example, an individual engaged in an aspect of an automated activity, such as Drilling sub-activity can be illustrated as shown Figure 1 below. As it observable in the figure above, the operators can simultaneously be engaged in two forms of activities. These are classified as follows:

a. Individual-oriented activity: This entails both physical and mental activities. The object of the physical activity is rock drilling while the object of mental activity is listening to communication models.

b. Social interaction: This entails collaboration between human physical activity and mental activity. The subject is the individual who is simultaneously engaged in a physical activity through the manipulation of digitized computer technology to programme robotic work tasks, and a mental activity through digitized communication models by listening to background music during work, as well as information transmission from the automated system control centers, and/or from colleagues approaching or leaving the individuals activity location inside the automated work system.

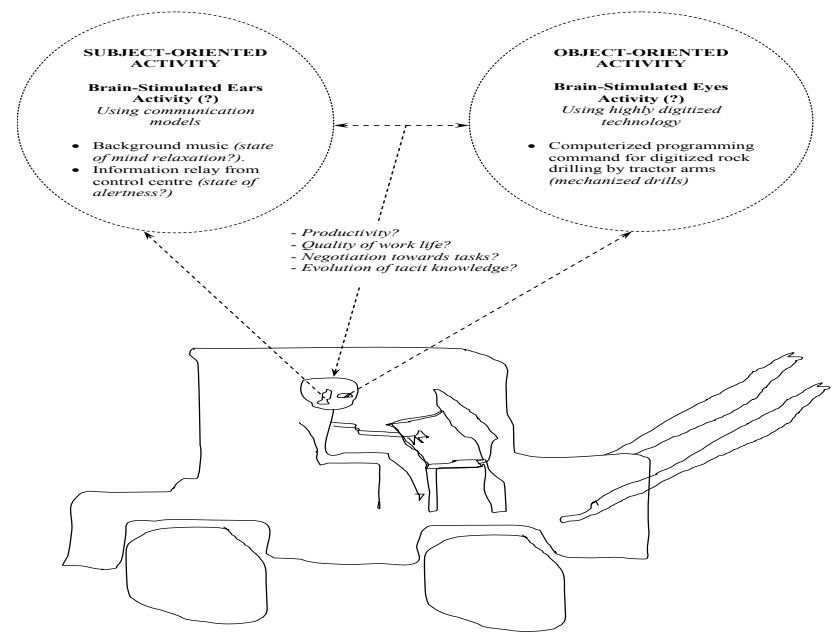

Figure I Operator engaged in highly mechanized deep mining activity of production drilling.

It is imperative from above that actions are fundamental components of activities and are subordinate to specific goals. The goal of an action, as explained by Leontiev (1974), is a conscious mental representation of the outcome to be achieved with its function being the orientation of the action. As such, in an automated mining activity, different actions may be undertaken to meet the same goal. This then implies that activities are realized as goal-oriented actions. Operations are execution ways of actions. They correspond with the way of goal achievement and are directly determined by the objective conditions in which the goal is given and has to be achieved. Operations may become routinized and unconscious with practice. Thus the first condition for any organizational activity is the presence of a need. In fact, an organizational activity is oriented by the transformation of a need into an objective (or motive). Though such a need can be sufficient to arouse and stimulate activities, it is unable to direct the concrete orientation of the stimulated activity. In large firms, each automated activity may constitute different actions with each action consisting of varieties of operations to be undertaken by different persons or groups, and/or mechanization process. Thus for an automated work system, the interdependent activities to be involved can be conceptualized from the learning to be made from existing automated work systems and innovative practice ideas outlined in existing literature. The development of SSAT is specifically oriented toward the analysis and design of the basic elements of human work activity with the following in mind-tasks, tools, methods, objects and results, and the skills, experience and abilities of subject who are involved in the activity. Its design-oriented analyses specifically focus on the interrelationship between the structure and self-regulation of work activity and the configuration of its material components. ${ }^{12}$

\section{Conclusion}

There is a current trend whereby most of the works within activity theory are restricted to the sociocultural approach to activity study, with the individual-psychological approaches to activity study, 
which are basic to the study of human work, usually not discussed. ${ }^{12}$ The individual-psychological analysis of activity includes the informational (cognitive), the morphological, the functional, and the parametrical methods of activity analyses. ${ }^{12}$ All of these methods in SSAT will be considered to be interdependent and will be logically organized according to stages and levels of the activity analysis. This allows one to tie together the obtained data into a holistic system. ${ }^{8}$ Therefore in the analysis of automated work activity, both the sociocultural and the individual-psychological analyses should be conducted. The main unit of analysis will be the organization. The sub-unit of analysis will be carried out at two levels. These are the "object oriented" activity level, and the "subject-oriented" activity level. As it is explained by Bedny et al., ${ }^{8}$ object-oriented activity is performed by a subject using tools on a material object, where the subject of activity is the individual or group of individuals engaged in that activity. In deep-mining activity, this can be ascribed to the various activates entailed in the total mining production process involving humans either operating directly underground with all the associated risks and hazards or operating in control rooms using technology. Similarly, subject-oriented activity (also known as social interaction) involves two or more subjects, and is constituted through information exchange, personal interactions and mutual understanding. During task performance, the object-oriented and subject-oriented aspects of activity continuously transform into one another. ${ }^{8}$

Thus in the analysis of object-oriented activity, inter-subjective relationships will also be considered. ${ }^{8,9}$ In both sub-analyses, the impact of activity contradictions ${ }^{13}$ should be assessed. Contradiction, as a source of tension that arises between elements of the automated activity system identify areas where the system's components no longer match the automated activities they are expected to model (i.e. a signification of misfit between elements within an automated activity, and/or between different automated activities). These contradictions therefore, manifest themselves as problems, ruptures, breakdowns, and clashes. ${ }^{13}$ As it is explained by Engeström, ${ }^{13}$ it is important to keep sight of the elements within the automated system. This is because many of the analytic strategies for examining mediated action between the human and the automated system can be made possible by isolating its elements. Such isolation allows various specialized perspectives to bring their insights to bear, and also serves as key to understanding how change occurs in the mediated action. Through such understanding, an innovative work organization that enhances social collaboration between automated systems and humans can be designed towards increased productivity.

\section{Acknowledgments}

No acknowledgement.

\section{Conflicts of interest}

No conflict of interest.

\section{References}

1. Abrahamsson L, Johansson J. Future Mining-Workers' Skills, Identity and Gender When Meeting Changing Technology. In: Proceedings, First International Future Mining Conference. 2008. p. 213-220.

2. Bassan J, Srinivasan V, Knights P, et al. A Day in the Life of a Mine Worker in 2025. Proceedings, First International Future Mining Conference. 2008. P. 71-78.

3. Abrahamsson L, Johansson B, Johansson J. Future of metal mining: sixteen predictions. International Journal of Mineral Engineering. 2009;1(3):304312 .

4. Jarzabkowski P. Strategy as social Practice: An Activity Theory Perspective on Continuity and Change. Journal of Management Studies. 2003;40(1):2355 .

5. Victor KaptelininKari, KuuttiLiam, Bannon. Activity Theory: Basic concepts and applications. International Conference on Human-Computer Interaction 1015. 1997.

6. Hendrick HW, Kleiner BM. Marcroergonomics: An introduction to work system design. 2001.

7. Lave J, Wenger E. Situated learning: Legitimate peripheral participation. UK: Cambridge University Press; 1991.

8. Bedny G, Karwowski W. A systemic-structural theory of activity: applications to human performance and work design. Boca Raton: CRC Press; 2007. p. 1-526.

9. Sanda MA. Exploring the concept of "Emerging Object of Activities" in understanding the complexity of managing organizational change. In: Symposium Book of Abstracts, Second Congress of the International Society for Cultural and Activity Research (ISCAR). 2008. 34 p.

10. Aldrich HE. Organizations and environments. USA: Stanford University Press; 2008. p. 1-416.

11. Thompson J. Organizations in action. 1967.

12. Bedny GZ, Karwowski W, Bedny M. The principle of cognition and behaviour: Implications of activity theory for the study of human work. International Journal of Cognitive Ergonomics. 2001;5(4):401-420.

13. Engeström Y. Expansive learning at work: Toward an activity theoretical reconceptualization. Journal of Education and Work. 2001;14(1):133-156. 